\title{
Young's Modulus of Iron-Silver Sheet Composites
}

\section{RATKE $\dagger$}

Max-Planck-Institut fuer Metallforschung, Institut fuer Werkstoffwissenschaften, Stuttgart, FRG

(Received March 5, 1988; in final form November 11, 1988)

Layered iron-silver sheet composites were prepared by hot extrusion and cold rolling of powder mixtures of various compositions. These in-situ deformation composites show a strong increase in Young's Modulus on addition of silver to pure iron and their elastic behaviour is anisotropic in the rolling plane. The deformation dependence of Young's Modulus as well as the planar anisotropy are discussed with a new theory of Bunge, which covers the experimental findings sufficiently.

KEY WORDS: Young's modulus, in-situ composites, elastic anomalies, texture.

\section{INTRODUCTION}

Two phase metallic composites which are prepared by common deformation of pre-compacted fine grained powder mixtures-a method developed by Wassermann in the sixties-show anomalies of their mechanical and physical properties compared to the bulk properties of their constituents (Wassermann, 1981; Frommeyer, 1976, 1977; Ratke, 1983). One essential feature of the microstructure of these in-situ deformation composites are fibres or layers of one component embedded into the other which may be as thin as $10 \mathrm{~nm}$, depending on the degree of deformation. In one of the first investigations on this new kind of composites (Wahl and Wassermann, 1970) wires of iron with silver of various compositions were

† Present address: Institute for Space Simulation DFVLR Cologne, FRG. 
produced. The authors showed there, that decreasing the thickness of the $\mathrm{Fe}$ or $\mathrm{Ag}$ fibres increases the tensile strength of the composites far beyond the values calculated from the strength of the bulk components. The materials became hard magnetic, the electrical resistivity increases due to enhanced scattering of electrons at the phase boundaries etc.

Frommeyer and Wassermann (1976) showed later that sheet composite materials can be prepared by the same technique. If powder mixtures are hot extruded to a rectangular bar and then further cold rolled to sheets of a few 100 micron thickness, compact materials with a layered structure are produced. The so processed material shows anisotropic elastic and plastic properties in the rolling plane (Welch, Ratke and Wassermann, 1984; Kohler, 1975).

It is found usually that Young's modulus and strength are higher in the transverse than in the rolling direction. This effect is in contrast to the behaviour of conventional laminated or fibre reinforced composites, which show either equal or appreciably lower strength and elastic modulus in the transverse direction.

In a previous study (Welch, Ratke and Wassermann, 1984) the texture development in $\mathrm{Fe}-\mathrm{Ag}$ sheet composites has been analyzed and the first results on Young's modulus were discussed. The deformation dependence and the planar anisotropy, however, were not well understood and are open to discussion for this kind of composites. Therefore the present study tries to explain the experimental findings with the help of a new theory due to Bunge (1988).

\section{EXPERIMENTAL PROCEDURE}

The composite sheets were prepared by hot extrusion of precompacted mixtures of Carbonyl-iron powder (mean particle diameter $13 \mu \mathrm{m}$ ) and silver powder (mean particle diameter $3.2 \mu \mathrm{m}$ ). Mixtures with $0,10,20$ and 30 vol. $\% \mathrm{Ag}$ were extruded at $800^{\circ} \mathrm{C}$ to rectangular bars $43 \times 6 \mathrm{~mm}$ (reduction of area, R.A. 94\%). Subsequent cold rolling consisted first of a reduction transverse to the extruding direction (R.A. 70\%) and then rolling parallel to the extrusion direction up to a total of $98 \%$ R.A. The microstructure 
was examined by light microscopy and SEM. The thickness of the Ag-layers was measured on the SEM-pictures by the line intercept method. The tensile strength of the composites was measured in the transverse and rolling direction with specimens according to the DIN 50125 procedure. Young's Modulus was measured with foil strain gauges using a full Wheatstone bridge and a medium carrier frequency amplifier. Specimens were taken at intervals between $70 \%$ and $98 \%$ cold reduction. The nomenclature in reference to the microstructure and the rolling process is explained in Figure 1.

The texture measurements were performed by X-ray and neutron diffraction. Incomplete polfigures were measured from the central plane of the composite sheets at each deformation stage. The silver has first been etched out of the polished texture specimens, in order to yield only the iron texture. It was intended to reduce the influence of anisotropic absorption by this procedure. This problem is inherent to texture determination of multiphase materials (especially fine eutectics and layered composites) by $\mathrm{X}$-ray methods and may cause serious errors in the texture determination as pointed out by Bunge and coworkers (1987). No estimate of this effect can be made for the specimens used here. Complete polfigures of the silver component were made with polished specimens by neutron diffraction.

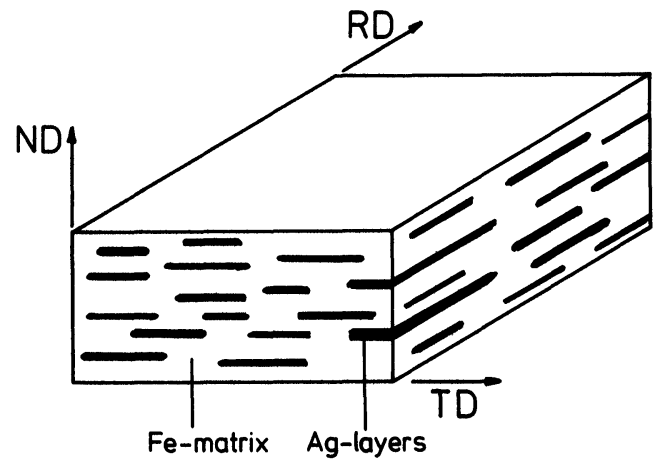

Figure 1 Schematic drawing of the microstructure and the reference frame used for the iron-silver sheet composites. 


\section{EXPERIMENTAL RESULTS}

The microstructure of all cold rolled sheets consists of silver layers embedded in an iron matrix. An example is given in Figure 2 (further details are described by Ratke (1984)). The originally spherical silver and iron powder particles are deformed into thin layers, much larger and wider than thick. Their reduction in thickness $\bar{L}_{\mathrm{Ag}}$ can be described approximately by

$$
\bar{L}_{\mathrm{Ag}}=\bar{L}_{\mathrm{Ag}}(0) \exp (-\varepsilon)
$$

where $\varepsilon=\ln \left(h / h_{0}\right)$ with $h_{0}$ the initial and $h$ the final thickness of the sheet. In reality the reduction is somewhat smaller (Ratke, 1984) at high degrees of cold rolling than predicted by Eq. (1) due to an increased work hardening of the silver layers.

The tensile strength of the composites shows a large increase with degree of deformation and a planar anisotropy, as shown in Figure 3. The transverse direction (TD) always has a higher strength than the rolling direction (RD). There is in addition a huge increase in strength and strain hardening of iron due to the alloying of "soft" silver (the essentials of this effect are discussed in (Ratke, 1984), where the addition of $20 \mathrm{vol} . \% \mathrm{Ag}$ leads to an even larger increase

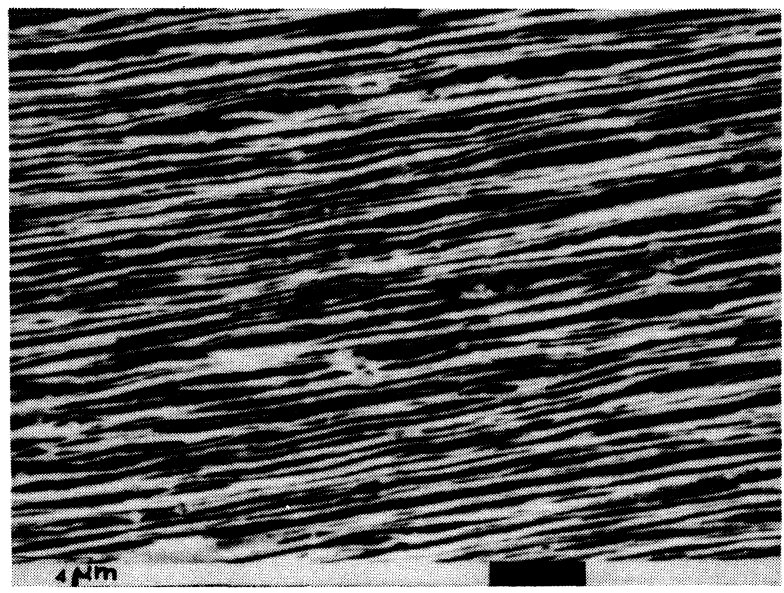

Figure 2 Microstructure of a cold rolled iron-silver sheet composite. The plane of view is parallel to the transverse direction. The bright phase is silver. 


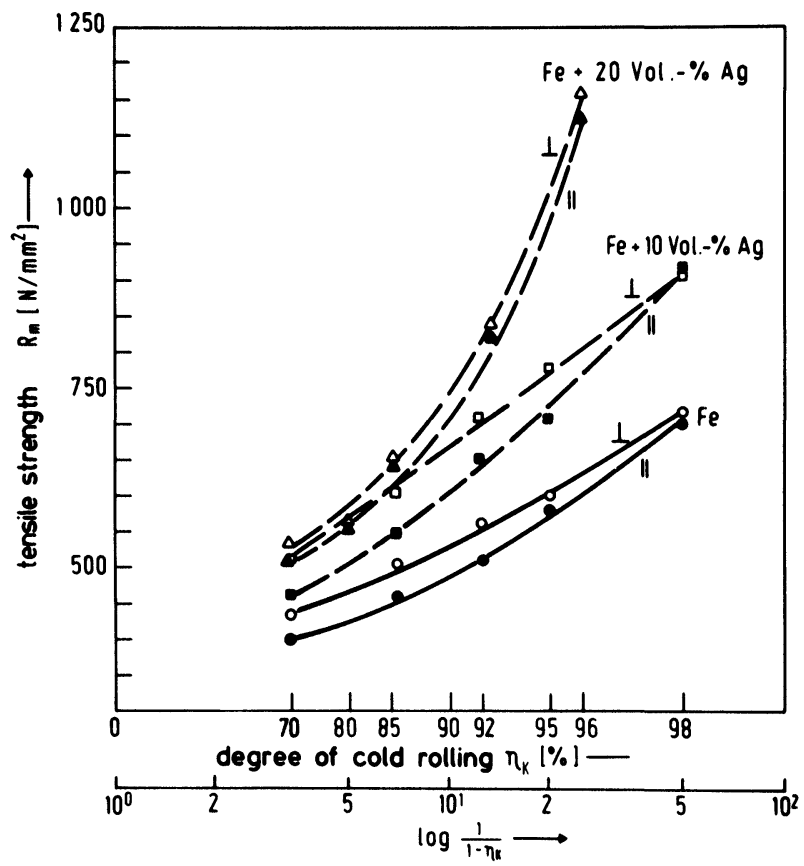

Figure 3 Tensile strength of various iron-silver sheet composites for different degrees of cold rolling compared with that of pure iron.

in strength than that of $10 \mathrm{vol} . \%$. The mean strain hardening rate $d \sigma_{B} / d \varepsilon$ is approximately $210 \mathrm{~N} / \mathrm{mm}^{2}$ per unit of natural strain for the composite with $10 \mathrm{vol} . \% \mathrm{Ag}$ and $440 \mathrm{~N} / \mathrm{mm}^{2}$ in the composite with 20 vol. $\%$ Ag.

The change in Young's Modulus $E$ with composition and reduction of thickness on degree of cold rolling $\varepsilon$ is shown in Figures 4a-d. Starting from pure iron, where $E$ is larger in TD than in RD with a small increase on deformation, sheet composites with 10 vol.\% $\mathrm{Ag}$ show the same anisotropy, $E$ however increases rapidly and almost linearly with strain to values higher than those of pure iron. Composites with 20 vol.\% Ag show the same increase with cold rolling, but no distinct anisotropy, whereas in sheets with $30 \mathrm{vol} . \% \mathrm{Ag}$ the anisotropy is inverse to that of pure iron.

The texture development is described in detail by Welch and coworkers (1984). It can be summarized to: The iron texture is 

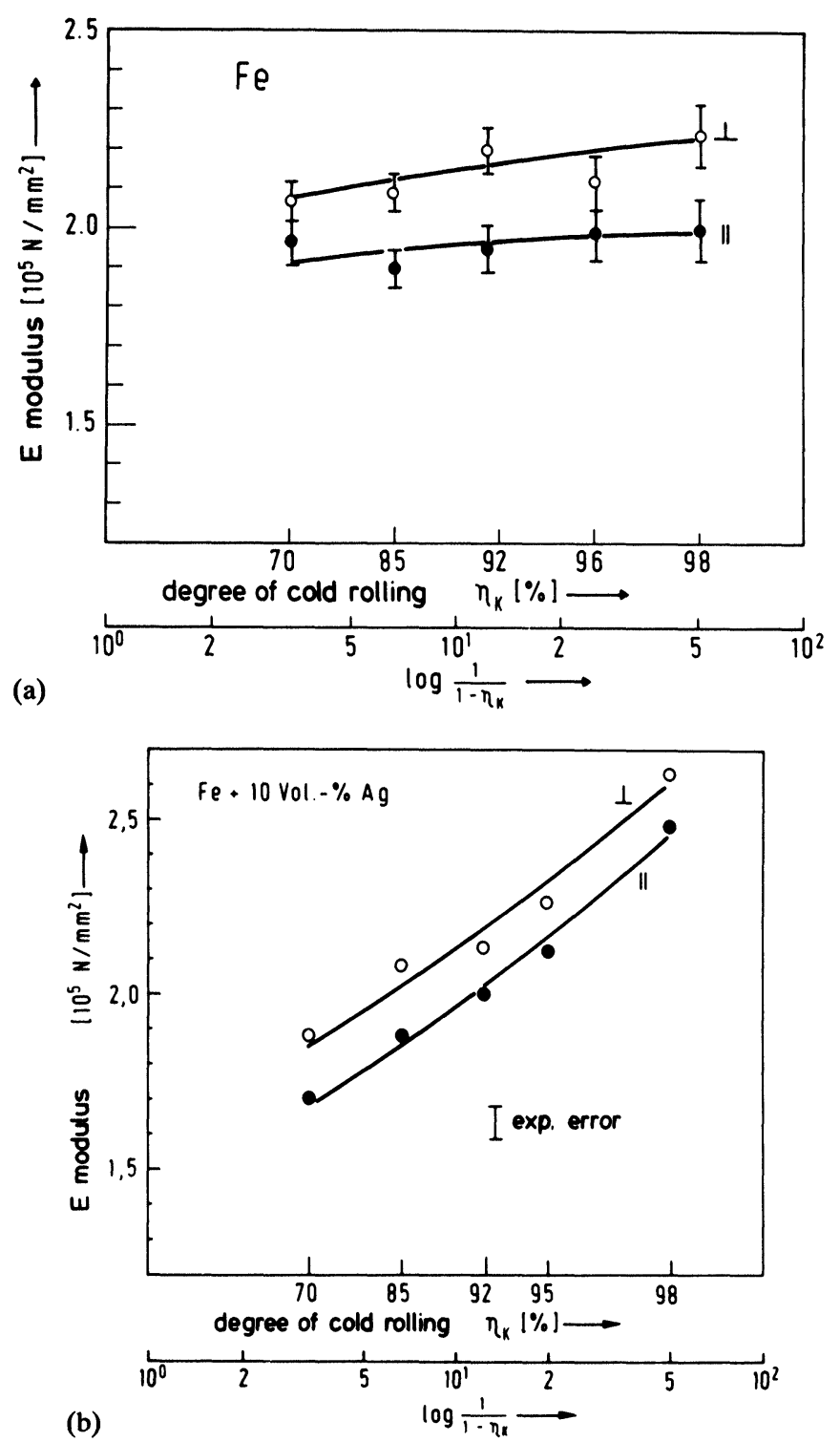

Figure 4(a-d) Young's modulus of the iron-silver composites. " $\|$ " denotes measurement parallel RD, “ $\perp$ " denotes that parallel TD. 

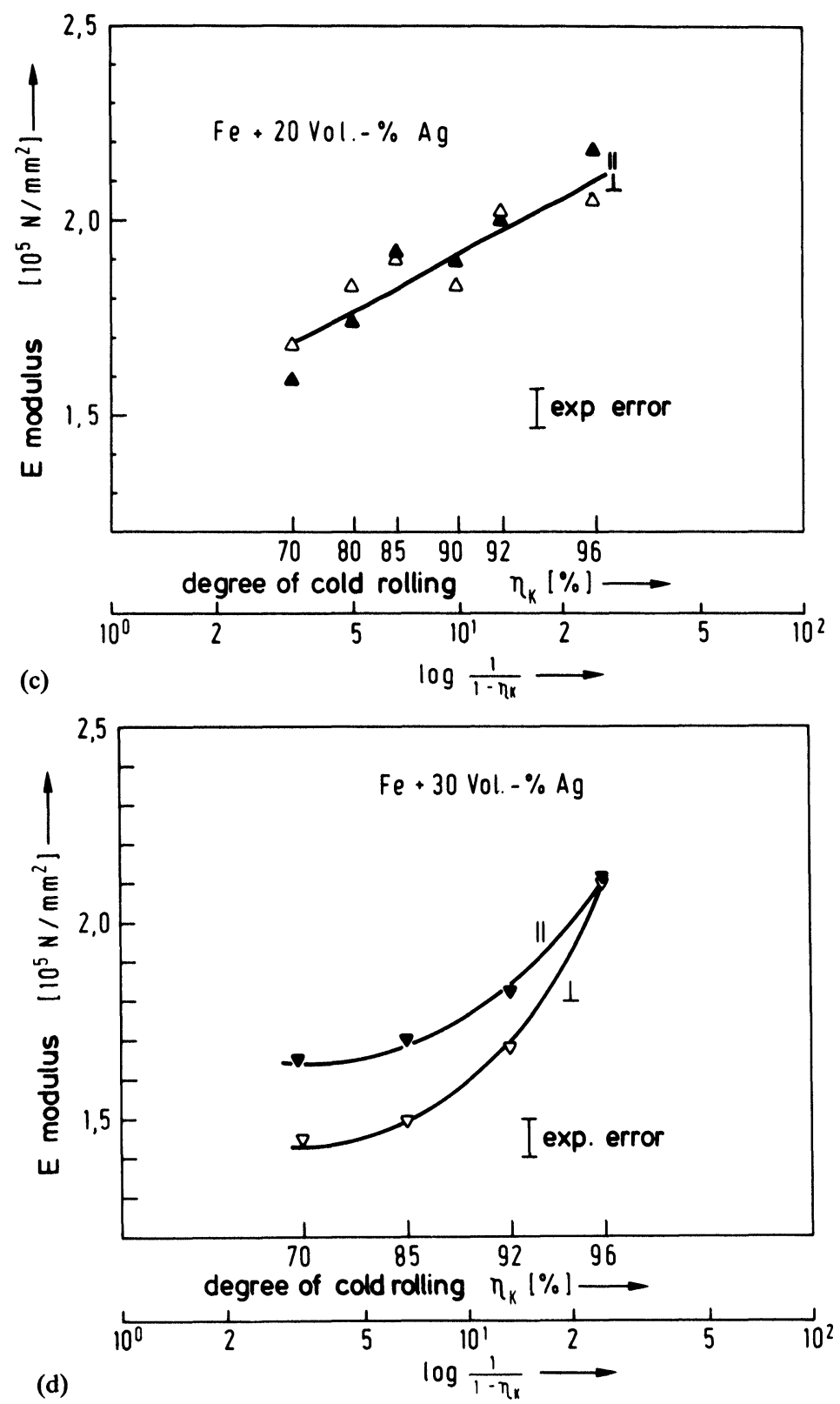
always well described by a (100) $\langle 110\rangle$ fibre texture, which becomes sharper with the addition of silver. The silver shows in principle a cube texture quite different from the rolling texture it would have developed if rolled alone. One should bear in mind, that all textures are essentially cross rolling textures, due to the deformation procedure used to make the sheet composites. Only the materials with the highest degree of cold rolling start to develop "normal" rolling texture, i.e. the effect of cross rolling diminishes.

With the measured texture and the calculated ODF it is possible to evaluate Young's modulus of each phase separately (with a Voigt, Reuss, Hill or another approximation) and then to combine them to the composite modulus with some assumptions on their microstructure (parallel, series or mixed mode alignment of the phases). Figure 5 shows the dependence of the iron $E$-modulus as calculated from the measured texture using Voigt's approximation. The important feature of this diagram is, that Young's modulus of the iron layers due to texture development during cold rolling is only a weak function of reduction of thickness. It is possible, that anisotropic absorption yields the constancy of Young's modulus at the higher degrees of deformation, because there the silver layers are very thin and their interlayer distances are small. In order to test this, one should perform texture measurements with neutrons.

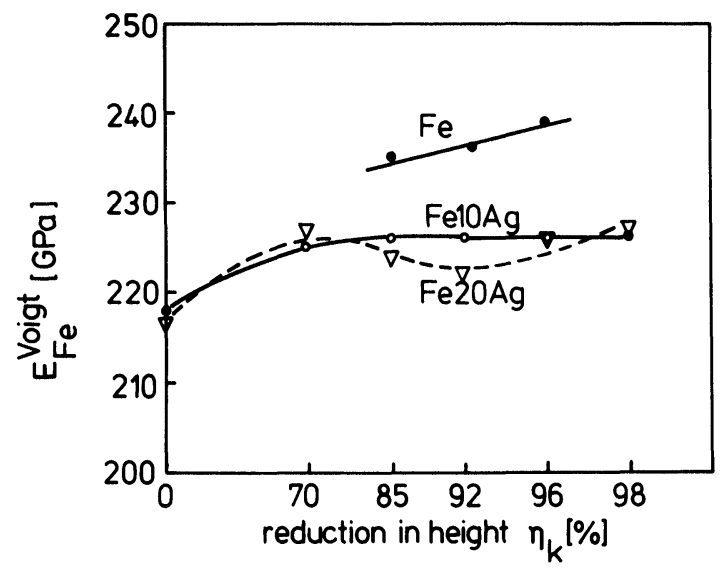

Figure 5 Young's modulus of the iron matrix as calculated from the texture measurement made by $\mathrm{X}$-ray in dependence on the reduction of height during cold rolling. 


\section{THEORETICAL CONSIDERATIONS}

The dependence of Young's modulus on degree of cold rolling shall be explained by a hypothesis originated by Bunge (1988). Its essential argument is: due to the common deformation of materials with different elastic moduli large internal stresses build up, leading to a change in Young's modulus compared to the residual stress free state. The $E$-modulus may attain higher or lower values compared to the undeformed state, depending on the sign of the internal stresses (compression or tension), the composition of the composite and the magnitude of the change of Young's modulus with internal stress. The calculations are based on the general law of mixture (Tamura et al., 1973; Haag, 1981). If $\bar{\sigma}$ is the average stress and $\bar{\varepsilon}$ the average strain in the composite, $\Phi_{1}, \Phi_{2}$ the volume fractions of the two phases in the composite, these laws read

and

$$
\bar{\varepsilon}=\Phi_{1} \bar{\varepsilon}+\Phi_{2} \bar{\varepsilon}_{2}
$$

$$
\bar{\sigma}=\Phi_{1} \bar{\sigma}_{1}+\Phi_{2} \bar{\sigma}_{2}
$$

After deformation by cold rolling residual stresses are left in both components $\sigma_{r}^{1}, \sigma_{r}^{2}$ equilibrating each other

$$
\sigma_{r}^{1} \Phi_{1}+\sigma_{r}^{2} \Phi_{2}=0
$$

The residual stresses can be expressed as

$$
\sigma_{r}^{k} \Phi_{k}=\bar{\sigma}_{k}(\varepsilon)-E_{0}^{k} \Delta \varepsilon
$$

with $E_{0}^{k}$ the Young's modulus of phase $k=1,2$ in the non-deformed state. Here we assume the phases to be arranged in parallel (validated by the microstructure), such that $\Delta \varepsilon$ is the residual strain remaining in both components after unloading

where

$$
\Delta \varepsilon=\bar{\sigma}(\varepsilon) / \overline{E_{0}}
$$

$$
\overline{E_{0}}=\Phi_{1} E_{0}^{1}+\Phi_{2} E_{0}^{2}
$$

Then the residual stresses in both components are given as

$$
\sigma_{r}^{k}=\sigma_{k}(\varepsilon)-E_{0}^{k} \bar{\sigma} / \overline{E_{0}}
$$

Now assume the elastic moduli of both phases being stress dependent as depicted in Figure 6. We develop $E^{k}$ into a Taylor 


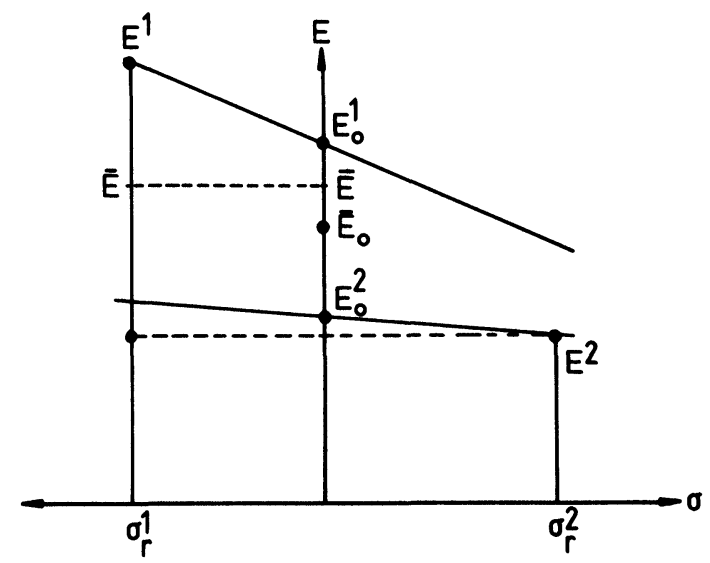

Figure 6 Schematic dependence of Young's modulus on stress for two different materials.

series up to first order

$$
E^{k}=E_{0}^{k}+\left(d E_{0}^{k} / d \sigma\right)_{\sigma=0} \sigma_{r}^{k}=E_{0}^{k}+d_{e}^{k} \sigma_{r}^{k}
$$

Then the overall modulus of the composite is given by

$$
\bar{E}=\overline{E_{0}}+\sum \Phi_{k} d_{e}^{k} \sigma_{r}^{k}
$$

or using Eq. (3)

or using Eq. (7)

$$
\bar{E}=\overline{E_{0}}+\Phi_{1} \sigma_{r}^{1}\left(d_{e}^{1}-d_{e}^{2}\right)
$$

$$
\bar{E}=\overline{E_{0}}+\Phi_{1}\left(\bar{\sigma}_{1}(\varepsilon)-\frac{E_{0}^{1} \bar{\sigma}}{\overline{E_{0}}}\right)\left(d_{e}^{1}-d_{e}^{2}\right)
$$

The essential feature of this equation is, that the magnitude of the effect of residual stress on Young's modulus depends most severely on the stress dependence of Young's modulus of both phases. The overall modulus of the composite may be either lower or higher than the value given by a simple law of mixture using the bulk residual stress free values of the components. The effect is governed by $d_{e}^{1}, d_{e}^{2}$, the volume content of second phase and by the yield stress $\sigma(\varepsilon)$ of the composite material. In addition there enters the stress-strain relationship of one component. This is, however, not the yield stress of the bulk constituent, but the yield stress of the 
phase inside the composite, i.e. it is an in-composite stress-strain curve and may therefore differ appreciably from the bulk flow curve. Since $d_{e}^{1}, d_{e}^{2}$ always are negative, it follows that $\Delta E=\bar{E}-\overline{E_{0}}$ is less than zero, if $d_{e}^{2}<d_{e}^{1}$ and $\bar{\sigma}_{1}(\varepsilon)-E_{0}^{1} \bar{\sigma} / \overline{E_{0}}=\alpha<0$ or $\Delta E>0$ if $\alpha>0$.

In order to check this theory with our results on $\mathrm{Fe}-\mathrm{Ag}$ composites we introduce into Eq. (11) some further knowledge on $\bar{\sigma}(\varepsilon)$ and $\bar{\sigma}_{1}(\varepsilon)$ (for reference see Ratke, (1984). The flow stress of the composite is described by a Hall-Petch type relationship

$$
\bar{\sigma}(\varepsilon)=\sigma_{\mathrm{ref}}+K_{v} \bar{L}_{\mathrm{Ag}}(\varepsilon)^{-1 / 2}
$$

with $K_{v}\left(\Phi_{1}, \Phi_{2}\right)$ the Hall-Petch constant and $\sigma_{\text {ref }}$ a reference value of the flow stress in the undeformed state. Using Eq. (1) we can rewrite Eq. (12)

$$
\bar{\sigma}(\varepsilon)=\bar{\sigma}_{0}+K_{v} / \bar{L}_{\mathrm{Ag}}(0)^{1 / 2} \cdot(\exp (\varepsilon / 2)-1)
$$

Values of $K_{v}$ have been measured (see Ratke, 1984), as well as the mean fibre thickness and the flow stress of the composites at zero deformation. A real complication is the unknown flow stress curve of silver inside the composite and the value of $d_{e}^{1}-d_{e}^{2}$. Assume for the silver layers a Hall-Petch relation

$$
\sigma_{\mathrm{Ag}}=\sigma_{\mathrm{Ag} 0}+K_{\mathrm{Ag}} \cdot d^{-1 / 2}
$$

with $\sigma_{\mathrm{Ag} 0}$ a friction stress and $K_{\mathrm{Ag}}$ a constant, known from the literature (Gil Sevillano et al., 1980). The grain or cell size is assumed to be a fraction $z$ of the layer thickness $\bar{L}_{\mathbf{A g}}$

$$
d=z \cdot \bar{L}_{\mathrm{Ag}}
$$

that is, we assume the cells or grains inside the silver layers being arranged in parallel with edge lengths $\bar{L}_{\mathrm{Ag}}$ and $d$. One may think of them being pillars with a rectangular cross section of $d$ times $d$ and a height of the layer thickness. The long axis of the pillars is tilted with respect to the long axis of the layers by 90 degrees. Inserting Eqs. (12) to (15) into Eq. (11) using the known values of Young's modulus in the hot extruded state of iron, the composites and that of silver calculated from the texture measurements, leaves an equation with three fit parameters $\sigma_{\mathrm{Ag} 0}, z, d_{e}^{1}-d_{e}^{2}$, where we set arbitrarily component 1 equal to silver and 2 equal to iron. $d_{e}^{1}-d_{e}^{2}$ should be independent of the degree of cold rolling and the silver 

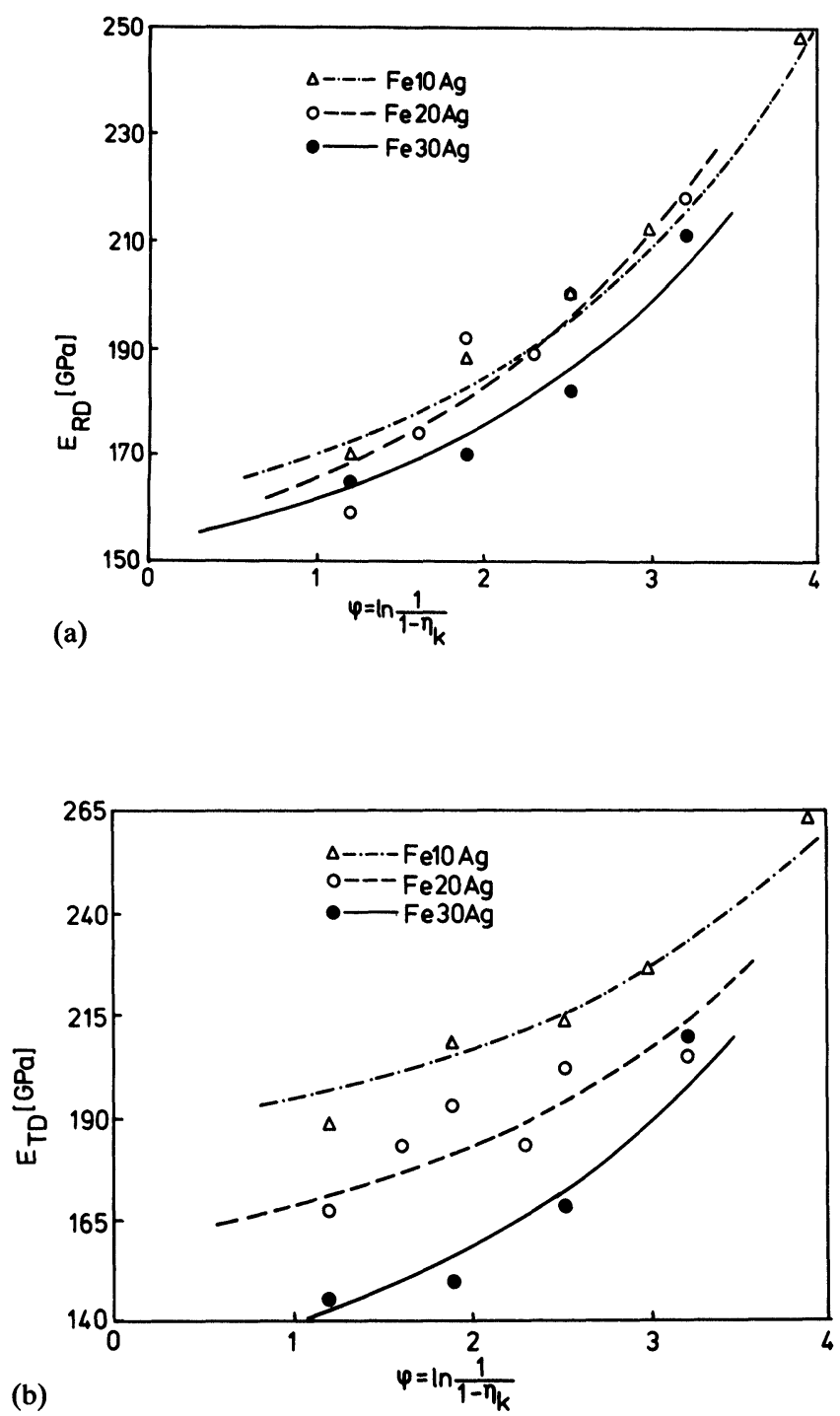

Figure 7 Numerical fit of Eqs. (11) to (14) to the experimental data given in Figures 4(b-d). Parameters used for the fits were $\left|d_{e}^{\mathrm{Fe}}-d_{e}^{\mathrm{Ag}}\right|=1200$; for iron with 10 vol.\% $\mathrm{Ag}-z(\mathrm{RD})=0.35, z(\mathrm{TD})=0.5, \sigma_{\mathrm{Ag}}(0)=0$; for iron with $20 \mathrm{vol} . \% \mathrm{Ag}-z(\mathrm{RD})=$ $0.27, z(\mathrm{TD})=0.33, \sigma_{\mathrm{Ag}}(0, \mathrm{RD})=60 \mathrm{MPa}, \sigma_{\mathrm{Ag}}(0, \mathrm{TD})=30 \mathrm{MPa}$; for iron with 30 vol. $\% \mathrm{Ag}-z(\mathrm{RD})=0.24, z(\mathrm{TD})=0.2, \sigma_{\mathrm{Ag}}(0, \mathrm{RD}=\mathrm{TD})=70 \mathrm{MPa}$. 
volume fraction. Figures $7 a$ and $b$ show fits of the theoretical expression to the experimental data sets for Young's modulus measured in the transverse and the rolling direction.

The theory is obviously able to describe the deformation dependence, the influence of volume fraction of silver and the planar anisotropy of the composite Young's modulus. The value chosen for $d_{e}^{1}-d_{e}^{2}$ was $1200, \sigma_{\mathrm{Ag} 0}$ varied with volume fraction and $z$. The parameters are given in the figure captions.

From the figures it seems, that Bunge's theory describes the experimental situation quite well. It is able to explain the huge Young's modulus anomaly of these composites, the increase of $E$ with degree of deformation, and the planar anisotropy. There is no need for new effects like phase boundaries behaving as a third component with extremely high elastic modulus (Welch et al., 1984). On comparing the fits with the experimental data one should keep in mind, however, that firstly there is a strong scatter on the data points and only a few degrees of deformation for each composition of the composites could be measured. Secondly, the in-situ or in-composite flow stress dependence of Young's modulus is rather arbitrary. If one tries to fit the experimental values with e.g. lower values for $d_{e}^{1}-d_{e}^{2}$ it is only possible if one chooses unrealistic values for $\sigma_{\mathrm{Ag} 0}$, being negative or using unrealistic, not measured values for the flow stress of the composite at zero deformation. In addition the value for the cell size within the silver layers is absolutely arbitrary. Measuring this in a transmission electron microscope would give a better estimate of the in-situ flow stress curve of silver.

The large value for $d_{e}^{1}-d_{e}^{2}$ may be reduced to more acceptable ones if one could take into account the deformation dependence of Young's modulus as induced by the texture changes. As pointed out above, the texture of the iron phase was obtained by X-ray diffraction. Although we etched the composites to make the surface layer of the texture samples silver free, we did not make a cross check with neturons to look for the effect of anisotropic absorption. Therefore the texture dependent increase of Young's modulus as shown in Figure 5 may be an underestimation of the real effect. If there would be a texture dependent increase in Young's modulus of approximately $10 \%$ this would reduce the value of $d_{e}^{1}-d_{e}^{2}$ to values which can be rationalized (see below). We will in addition em- 
phasize, that the fits are per se not unique. If the number of data points would be higher, a multivariate least square fit would be meaningful. No such attempt was made here. The fits were performed interactively on a computer.

Despite these uncertainties we are convinced, that the physical basis of Bunge's theory is experimentally well founded by the large number of investigations made with this kind of composites. Hunger, Frommeyer and Wassermann (1979) measured internal strains in cold drawn $\mathrm{Ag}-\mathrm{Cu}$ wires of eutectic composition by $\mathrm{X}$-ray line broadening. They found a large increase in relative lattice constant of $\mathrm{Ag}$ with increasing degree of deformation up. Such large internal strains correspond to large internal stresses and therefore give a change in elastic modulus as assumed in Eq. (8).

An additional confirmation of the concept of Bunge comes from a work of Jankowski and Tsakalakos (1985). They studied the effect of strain on the elastic constants of noble metals $(\mathrm{Cu}, \mathrm{Ag}, \mathrm{Au})$ in order to understand the well-known elastic anomaly of layered composition modulated metallic films. Using a pseudopotential energy calculation for the crystal energy, they calculated the elastic constants as a function of strain either compressive or tensile. The essential result of their calculation is a strong variation of biaxial modulus with strain approximately linearly dependent on it. The change of modulus with strain is negative and of the order $d E / d \varepsilon=-3.910^{6} \mathrm{~N} / \mathrm{mm}^{2}$ and percent strain for silver. Thus one estimates a value of $d E / d \sigma=(d E / d \varepsilon) / E_{0}=50$ for silver. No estimate for iron can be made. The values used here for a fit would assume at least a 10 times higher effect of stress on Young's modulus for iron.

A further remark is necessary. The experimental results on Young's modulus of in-situ deformation composites are a bit contradictory. Mordike, Bergmann and Bormann (1981) found an increase of the elastic modulus for $\mathrm{Cu}+30 \mathrm{wt} . \% \mathrm{Nb}$ wires. Bevk et al. (1978) reported an increase for wires of $\mathrm{Cu}+18.2 \mathrm{wt} . \% \mathrm{Nb}$ with degree of cold drawing. The same authors reported three years later quite contradictory results with Cu-alloys having 7.5 and $15 \mathrm{wt} . \%$ $\mathrm{Nb}$. Then they found a decrease of Young's modulus up to $40 \%$ (Bevk, 1983). Frommeyer and Wassermann (1975) reported for eutectic $\mathrm{Ag}-\mathrm{Cu}$ wires first a decrease of $E$ with $\varepsilon$, and after a critical degree of deformation an increase. The same behaviour was 
measured with $\mathrm{Ag}-\mathrm{Cu}$ foils (Frommeyer and Wassermann, 1976) and $\mathrm{Fe}-\mathrm{Cu}$ sheet composites (Kohler, 1975). Kohler measured Young's modulus of iron alloyed with $\mathrm{Cu}$ in the same way as done in this study with silver. He used composites of iron with 30 and $70 \% \mathrm{Cu}$. For degrees of cold rolling smaller than $95 \%$ he found a decrease of Young's modulus and afterwards a huge increase of the same order as reported here for $\mathrm{Fe}-\mathrm{Ag}$ composites. It is worth noting, that his copper powder had a grain size of 70 to $110 \mu \mathrm{m}$. Therefore he needed a higher degree of cold rolling to obtain a layer thickness comparable to the Ag-layers thickness in this study even at the lowest used degree of cold rolling used here.

These different results are understandable with the residual stress theory of Bunge presented here in an abbreviated form (for details see his forthcoming paper). Depending on volume fraction, the parts with compression or tension stresses change their proportion (Eq. (3)), leading to a decrease in the composite overall modulus (Eq. (11)). The in-situ flow stress curve is also affected by the volume fraction of second phase. Additionally, one has to take into account the interlayer distance, the volume fraction of second phase and the morphology of the composite, especially deviations from parallel alignment of phases.

\section{Acknowledgements}

The author gratefully acknowledges the discussions with H. J. Bunge about his new theory over the last three years and the possibility of seeing the manuscript of his forthcoming paper prior to publication.

\section{References}

Bergmann, H. W., Mordike, B. L. and Bormann, R. (1981). Mechanische Eigenschaften von $\mathrm{Cu}-\mathrm{Nb}$ und $\mathrm{Cu}-\mathrm{Nb}_{3} \mathrm{Sn}$ Verbundsupraleitern, in: Verbundwerkstoffe, DGM, Oberursel, FRG, pp. 257-269.

Bevk, J., Harbinson, J. P. and Bell, J. L. (1978). Anomalous increase in strength of in situ formed $\mathrm{Cu}-\mathrm{Nb}$ multifilamentary composites, J. Appl. Phys. 49, 60316038.

Bevk, J. (1983). Ultrafine filamentary Composites. In Ann. Rev. Mater Sci. 13, 319-338.

Bunge, H. J. Textures and Microstructures. To be published.

Bunge, H. J., Liu, Y. S. and Hanneforth, R. (1987). Anisotropic Absorption of X-rays in Polyphase Materials, Scripta met. 21, 1423-1427.

Frommeyer, G. and Wassermann, G. (1975). Microstructure and Anomalous 
Mechanical Properties of in situ-Produced Silver-Copper Composite Wires. Acta metall. 23, 1353-1360.

Frommeyer, G. (1976). Eigenschaftanomalien höchstverformter Silber-Kupfer Verbunddrähte, Z. Werkstofftechn. 7, 145-153.

Frommeyer, G. and Wassermann, G. (1976). Herstellung und Eigenschaften von mettalischen Verbundfolien $Z$. Werkstofftechn. 7, 154-156.

Frommeyer, G. (1977). Festigkeitsverhalten, elektrische Leitfähigkeit und magnetische Härtung höchstverformter $\mathrm{AgNi}$-, $\mathrm{CuFe}$ - und $\mathrm{AgCu}-\mathrm{Verbundfolien}$. Metall. 31, 732-735.

Frommeyer, G., Hunger, G. and Wassermann, G. (1979). Quantitative Bestimmung von Gitterdefektparametern hochverformter Silber-Kupfer-Faserverbunddrähtemittels Analyse von Interferenzlinienprofile, Z. Metallkde. 70, 481-485.

Gil Sevillano, J., Van Houtte, P. and Aernoudt, E. (1980). Large Strain Work Hardening and Textures, Progr. Mat. Sci. 25, 69-412.

Haag, J. (1981). Prinzipielle Grenzen der Mischungsregel für die Beschreibung der mechanischen Eigenschaften von Verbunden, in: Verbundwerkstoffe, DGM Oberursel FRG, pp. 33-62.

Jankowski, A. F. and Tsakalakos, T. (1985). The effect of strain on the elastic constants of noble metals, J. Phys. F 15, 1279-1292.

Kohler, W. (1975). Aufbau und Eigenschaften von hochverformten Eisen-Kupfer Verbundfolien, Master thesis, Clausthal, FRG 1975.

Ratke, L. (1983). Anomale Eigenschaften von Phasengrenzflächen-Werkstoffen Metall 37, 799-804 and 1019-1022.

Ratke, L. (1984). Anisotropic mechanischer und physikalischer Eigenschaften von Fe-Ag-Verbundblechen Z. Metallkde. 75, 529-534.

Tamura, I., Tomota, Y. and Ozawa, H. (1973). Strength and Ductility of Fe-Ni-C Alloys composed of Austenite and Martensite with Various Strength. In: Proc. of the Int. Conf. on Strength of Metals and Alloys, Cambridge UK, Vol. 1, pp. 611-615.

Wahl, H. P. and Wassermann, G. (1970). Anomalien der Eigenschaften dünner Drähte aus Eisen-Silber-Legierungen Z. Metallkde. 61, 326-339.

Wassermann, G. (1981). Probleme bei der Herstellung von Verbundwerkstoffen durch Verformung, in: Verbundwerkstoffe, DGM Oberursel, FRG, pp. 63-69.

Welch, P. I., Ratke, L. and Wassermann, G. (1984). The Effect of Deformation on Young's Modulus in Iron-Silver Sheet Composites, in: Proc. VII Int. Conf. on Textures of Materials, Netherlands Soc. Mat., Eds. C. M. Brakman, T. Jongenburger and E. J. Mittermeyer, pp. 675-680. 